\title{
The Efficacy of Two Novel Retreatment Systems in the Removal of Root Canal Obturating Materials (An In vitro Study)
}

\author{
Rasha Sameh (D), Mohamed Omaia* (D) \\ Department of Endodontics, Faculty of Dentistry, October 6 University, Cairo, Egypt
}

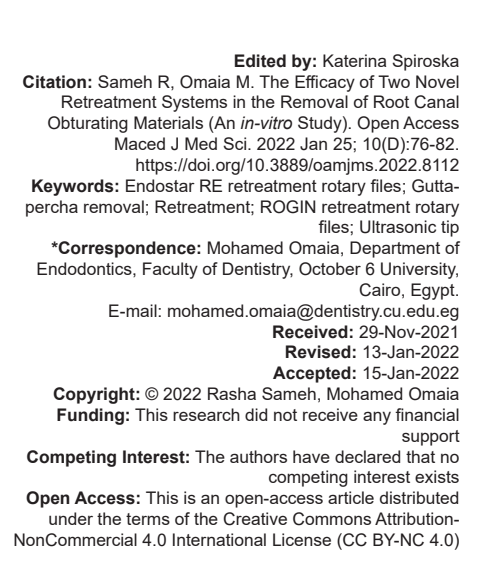

\begin{abstract}
BACKGROUND: The complete removal of root filling material is one of the main goals of non-surgical endodontic retreatment. Thus, the development of new techniques and instruments aiming to promote this task presents clinical significance.

AIM: The purpose of the study was to assess the amount of residual root canal filling materials (gutta-percha/sealer) after using two different endodontic retreatment systems and ultrasonic tip.

METHODS: Forty-five mandibular premolar teeth were mechanically instrumented and obturated. Retreatment was performed using two different Endostar RE (Group 2), Rogin retreatment system (Group 3), and ultrasonic tip (Group 1). Roots were separated buccolingually into two halves. A digital camera connected to the stereomicroscope captured images to each half. Image-J software was used to evaluate and measure the areas with remaining filling material in each third (cervical, middle, and apical).

RESULTS: Data analysis revealed significant differences between the groups in the coronal, middle, and apical thirds $(p<0.05)$. The ultrasonic retreatment tips $(\mathrm{G} 1)$ were significantly more efficient in removing the gutta-percha and sealers compared to the Rogin (G3) and Endostar (G2) retreatment endodontic kits.

CONCLUSIONS: All the file systems left some filling material in the canals. Ultrasonic retreatment tip had maximum efficacy for the removal of filling materials in comparison with the retreatment file systems under
\end{abstract} investigation.

\section{Introduction}

The primary reason for an endodontic failure is the persistence or regrowth of bacteria within the root canal system which requires retreatment [1], the success of retreatment depends on the efficient removal of the entire root filling material from the root canal system [2].

Different techniques and materials allow removal of the entire root canal filling material: Hand or mechanical (rotatory or reciprocation) instrumentation used commonly on the primary endodontic treatment. While, rotary files, ultrasonic tips, heated pluggers, and Nd: YAG lasers were designed explicitly for retreatments. Gutta-percha removal can be challenging, and the difficulty is related to the quality of the previous treatment, time elapsed since primary therapy and anatomical complexity of the canal system [3], [4].

Incomplete removal of the filling materials may influence treatment outcomes as the presence of root canal obturation materials may prevent the contact of the irrigation solutions with persistent microorganisms [5].
Use of hand files for the retreatment procedure of the root canals with well-condensed root filling material with or without solvent is tiresome and time consuming [6]. Therefore, it is important to find the proper rotary file system for easy and effective removal of remnants from the root canal system [7]. One major advantage of using rotary instruments for gutta-percha removal is their fast action [8].

Several companies produce $\mathrm{Ni}-\mathrm{Ti}$ rotary systems for root canal retreatment as Rogin retreatment $\mathrm{Ni}-\mathrm{Ti}$ rotary instrumentation system which consists of three files and the Endostar RE Retreatment Rotary $\mathrm{Ni}$-Ti instrumentation system which consists of four files [8], [9], [10].

The aim of the present study was to compare the gutta-percha removal efficacy of ultrasonic tip (G1), Endostar RE retreatment (G2), and Rogin (G3) retreatment $\mathrm{Ni}-\mathrm{Ti}$ rotary instrumentation system retreatment files from the root canals. The null hypothesis was that there would be no statistically significant difference in gutta-percha removal efficacy between ultrasonic tip, Endostar RE retreatment, and Rogin retreatment $\mathrm{Ni}-\mathrm{Ti}$ rotary instrumentation system retreatment files from the root canals. 


\section{Materials and Methods}

\section{Sample size}

In the current study, a total sample of six subjects per group yields $19 \%$ power to detect differences among the means versus the alternative of equal means using an $F$ test with a 0.05000 significance level. The size of the variation in the means is represented by their standard deviation which is 0.82 . The common standard deviation within a group is assumed to be 1.00 [11]. Thus, the sample size is set to 15 sample per group with a total of 45 sample for all the groups (Table 1). The sample size was calculated using $\mathrm{G}^{*}$ power program (Version 3.1.9.2/2014).

Table 1: Sample classification and group sample size

\begin{tabular}{llll}
\hline Classification Criteria & $\begin{array}{l}\text { Ultrasonic } \\
\text { tip (G1) }\end{array}$ & $\begin{array}{l}\text { Endostar } \\
\mathrm{RE}(\mathrm{G} 2)\end{array}$ & $\begin{array}{l}\text { Rogin retreatment } \\
(\mathrm{G} 3)\end{array}$ \\
\hline $\begin{array}{l}\text { Area of reaming material } \\
\text { per root section }\end{array}$ & 15 & 15 & 15 \\
\hline
\end{tabular}

\section{Selection and preparation of teeth}

Forty-five recently extracted single-rooted mandibular premolars due to prosthodontics or periodontal disease were collected from oral and maxillofacial surgery clinic. Periodontal scaler was used to mechanically clean the root surface from soft tissues and calculus. Radiographs from different angulations (buccolingual and mesiodistal) were done to ensure that the samples comprised mature apices with no calcification, root fracture, cracks, and/or internal resorption.

The exclusion criteria were as follows: Teeth with preexisting fractures or cracks, teeth with root caries, previously endodontically treated teeth, teeth with intracanal calcification, teeth with external resorption, teeth with internal resorption, carious teeth, teeth with an open apex, and teeth with previous restorations.

Samples were immersed in sodium hypochlorite solution for not more than 30 min and cleaned from softtissue attachments then washed and immersed in saline solution at room temperature to prevent dehydration till the time of use. Preparation of the access cavities was completed using high-speed diamond burs and copious amount of water coolant. For the working length (WL) determination, flattening of the crowns was performed to provide a reference point.

After cleaning and shaping procedures, the specimens were randomly distributed into three groups (using the software http://www.random.org) according to retreatment system used.

\section{Root canal preparation}

The patency of the root canals was checked by inserting a $15 \mathrm{~K}$-file into the canals until it was noticeable at the apical foramen. Canals that did not permit the insertion of $15 \mathrm{~K}$-file to the apex or those with apex wider than $20 \mathrm{~K}$-file were excluded from the study. The WL for canal preparation was created by subtracting $1 \mathrm{~mm}$ from the file length. Root canals were then prepared with ProTaper Next Ni-Ti rotary system (Dentsply Maillefer, Ballaigues, Switzerland) with the sequence $S X(19,0.04), X 1(17,0.04), X 2$ $(25,0.06)$ and $X 3(30,0.07)$ at speed of $300 \mathrm{rpm}$ and torque of $2.5 \mathrm{Ncm}$. ProTaper next instruments were operated using the X-Smart Plus motor (Dentsply Maillefer, Ballaigues, Switzerland) irrigation was done using $2 \mathrm{ml}$ of $2.6 \% \mathrm{NaOCl}$ between each file, then after completing the instrumentation procedures, $3 \mathrm{ml}$ of $17 \%$ ethylenediaminetetraacetic acid was applied for smear layer removal for $1 \mathrm{~min}$, followed by distilled water, and then the canals were irrigated with $2 \mathrm{ml}$ of $2.6 \% \mathrm{NaOCl}$ followed by $10 \mathrm{ml}$ of distilled water as a final flush.

\section{Root canal obturation}

Canals were dried with paper points and then obturated by modified single cone technique using X3 gutta-percha points, ADSEAL resin sealer (META BIOMED Co., Chungbuk, Korea) and auxiliaries gutta-percha cones size 25 (META BIOMED Co., Chungbuk, Korea \#DM-15-4). Roots were radiographed in multiple angulations (buccolingual and mesiodistal) to verify the competency of obturation, the access cavity was sealed with cavit (3M ESPE, St. Paul, MN, USA). All the teeth were incubated at $37^{\circ} \mathrm{C}$ and $100 \%$ humidity for 4 weeks to ensure full setting of the sealer.

To mimic the thermal changes that occur in the oral cavity, the specimens were subjected to thermal cycling (Veriti thermal cycler) between 5 and $55^{\circ} \mathrm{C}$ for with 20-60 s dwell times, with changes in light, temperature, pressure, and humidity in an accelerated artificial aging chamber.

\section{Root canal retreatment \\ Group I: Ultrasonic retreatment tip}

As the use of ultrasonic in retreatment is actually an unfamiliar territory in endodontics, ultrasonic endodontic retreatment tip E-7 (16 mm length and $0.6 \mathrm{~mm}$ diameter at tip) (NSK, Nakanishi, Japan) was used for the removal of root canal filling material. The root canals were irrigated for $10 \mathrm{~s}$ with $2 \mathrm{~mL}$ of $2.6 \% \mathrm{NaOCl}$ during retreatment and then with saline after the use of the tip. After instrumentation, the canals were irrigated with $2 \mathrm{~mL}$ of $17 \%$ EDTA and $5 \mathrm{~mL}$ of distilled water.

\section{Group II: Endostar RE Re endo retreatment} rotary $\mathrm{Ni}-\mathrm{Ti}$ instrumentation system

Endostar retreatment files (Endostar, Poldent Co., Warsaw, Poland) were used in gentle in-and-out motion at constant speed of $300 \mathrm{rpm}$ as per the manufacturer's recommendation. R1 (size 30; 12\% taper) (length $17 \mathrm{~mm}$ ) 
was used 1-3 $\mathrm{mm}$ beyond the pulp chamber to remove the initial bulk of obturation material, R2 (size 30; 8\% taper) (length $25 \mathrm{~mm}$ ) was used in the coronal third, R3 (size 30; 6\% taper) (length $25 \mathrm{~mm}$ ) in the middle third, and R4 (size 30; 4\% taper) (length $25 \mathrm{~mm}$ ) in the apical third as specified by the manufacturer, with every instrument change, the root canals were irrigated for $10 \mathrm{~s}$ with $2 \mathrm{~mL}$ of $2.6 \% \mathrm{NaOCl}$ during retreatment and then with saline after the use of each file. After instrumentation, the canals were irrigated with $2 \mathrm{~mL}$ of $17 \%$ EDTA and $5 \mathrm{~mL}$ of distilled water.

\section{Group III: Rogin retreatment Ni-Ti rotary instrumentation system}

Rogin retreatment files (Shenzhen Rogin Medical Co., China) were used in crown-down manner in a brushing motion at constant speed of $300 \mathrm{rpm}$ and torque of $2.5 \mathrm{Ncm}$ as per the manufacturer's recommendation. D1 (size 25; 9\% taper) (length $16 \mathrm{~mm}$ ) was used in the coronal third, D2 (size 25; 8\% taper) (length $18 \mathrm{~mm}$ ) in the middle third, and D3 (size 20; 7\% taper) (length $22 \mathrm{~mm}$ ) in the apical third as specified by the manufacturer, with every instrument change. The root canals were irrigated for $10 \mathrm{~s}$ with $2 \mathrm{~mL}$ of $2.6 \% \mathrm{NaOCl}$ during retreatment and then with saline after the use of each file. After instrumentation, the canals were irrigated with $2 \mathrm{~mL}$ of $17 \%$ EDTA and $5 \mathrm{~mL}$ of distilled water.

Files were wiped regularly using gauze piece soaked in normal saline to remove obturation material and debris.

\section{Stereomicroscopic evaluation of root canal cleanliness}

Longitudinal groove was created in each root in buccolingual direction using a diamond disc (Kerr dental, Switzerland) to a depth just before reaching the canal space. The roots were split into two halves using mallet and chisel. Each half was examined with a digital camera connected to the stereomicroscope (Olympus, SZX9, Tokyo, Japan) with 15x and images were captured. The areas with remaining obturation material (gutta-percha/sealer) in each root canal third were identified, outlined, and assessed by two blinded observers with no attempt to differentiate between gutta-percha and sealer segment (Figure 1).

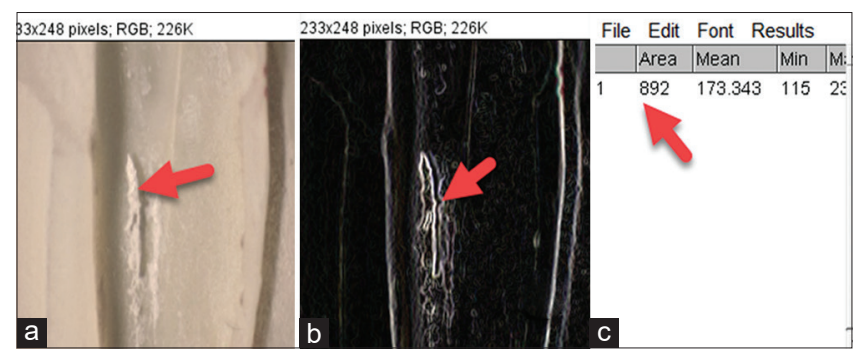

Figure 1: Measuring area of the remaining obturation material using Image-J software
All images were analyzed using Image-J software (Image-J, v1.44), to measure the area of the remaining obturation material in each third (coronal, middle, and apical). The ratio of the area of the remaining filling in pixels/the area of the canal segment in pixels was analyzed and expressed as the percentage of the residual filling material in each canal segment.

\section{Observer calibration}

Data reliability assessment is performed using an intraexaminer calibration which was assessed by inter-rater reliability. Observer's calibration was done by two dentists. All examiners followed the same written guideline, which was given to them before the procedure. This was conducted by evaluating five random scans in estimating the area. The assessment for the images was done twice, including a 1-week interim between evaluations. Any disagreement encountered in the image interpretation was discussed.

\section{Statistical analysis}

Numerical data of the area percentage of the remaining filling material were presented as mean and standard deviation (SD) values. Data were investigated for normality using Kolmogorov-Smirnov test and were found that it came from a population with normal distribution. Oneway analysis of variance (ANOVA) followed by Tukey's post hoc test was used for intergroup comparisons while oneway repeated measures ANOVA was used for within group comparisons for the examined parameter. Statistical analysis was performed with IBM $®$ SPSS $®$ Statistics Version 26 for Windows. The significance level was set at $p \leq 0.05$.

\section{Results}

The kappa value was calculated to estimate the reliability of the measurements taken by the two observers. In this study, the value of the kappa test was completely reliable for coronal, middle, and apical thirds evaluation, kappa $=1.0,1.0$, and 0.95, respectively.

Mean and standard deviation (SD) values for the area percentage of the remaining filling material in different groups are presented in Table 2 and Figure 2.

Table 2: Mean and standard deviation (SD) values for area \% of the remaining filling materials in different groups

\begin{tabular}{|c|c|c|c|c|c|}
\hline \multirow{2}{*}{$\begin{array}{l}\text { Root } \\
\text { section }\end{array}$} & \multicolumn{3}{|c|}{ Area \% (Mean \pm SD) } & \multirow[t]{2}{*}{ F-value } & \multirow[t]{2}{*}{$\mathrm{p}$-value } \\
\hline & $\begin{array}{l}\text { Ultrasonic tip } \\
\text { (G1) }\end{array}$ & $\begin{array}{l}\text { Endostar RE } \\
\text { (G2) }\end{array}$ & $\begin{array}{l}\text { Rogin } \\
\text { retreatment (G3) }\end{array}$ & & \\
\hline Coronal & $3.647 \pm 0.781^{\mathrm{aA}}$ & $10.273 \pm 1.863^{\mathrm{aB}}$ & $7.987 \pm 1.595^{\mathrm{aC}}$ & 76.944 & $<0.001^{*}$ \\
\hline Middle & $5.453 \pm 1.172^{\mathrm{bA}}$ & $14.067 \pm 1.957^{\mathrm{bB}}$ & $11.133 \pm 1.779^{\mathrm{bC}}$ & 103.146 & $<0.001^{*}$ \\
\hline Apical & $6.097 \pm 1.847^{\mathrm{bA}}$ & $16.307 \pm 5.585^{\mathrm{bB}}$ & $15.533 \pm 2.924^{\mathrm{cC}}$ & 33.700 & $<0.001^{*}$ \\
\hline Overall & $5.066 \pm 1.678$ & $13.549 \pm 4.311$ & $11.551 \pm 3.786$ & 74.301 & $<0.001^{*}$ \\
\hline F-value & 13.463 & 10.875 & 45.338 & & \\
\hline p-value & $<0.001^{*}$ & $<0.001^{*}$ & $<0.001^{*}$ & & \\
\hline
\end{tabular}




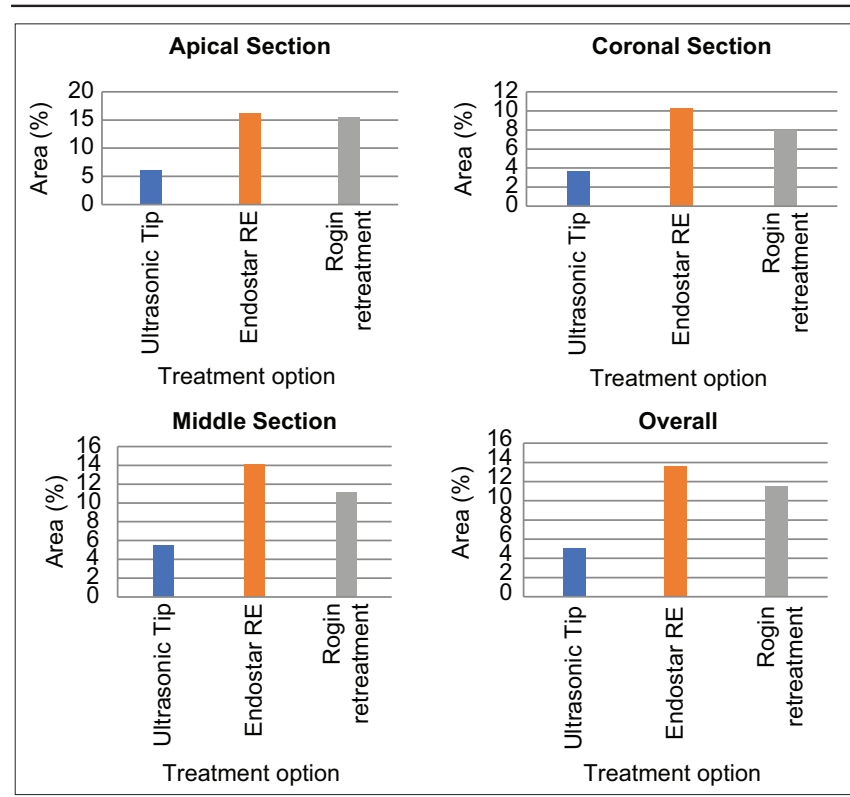

Figure 2: Bar chart showing average area\% of filling material in different groups

Results showed a statistically significant difference between different groups $(p<0.001)$ as regard the total area percentage of the remaining filling material. Endostar RE (G2) showed the highest value of the remaining filling material $(13.549 \pm 4.311 \%)$, followed by Rogin retreatment (G3) $(11.551 \pm 3.786 \%)$, while ultrasonic Tip (G1) showed the lowest mean value $(5.066 \pm 1.678 \%)$. Pairwise comparisons showed ultrasonic tip to have significantly less residual material value than canals cleaned with other systems $(p<0.001)$. Regarding the area, percentage of the remaining filling material at different root canal levels. There was a significant difference between the different root levels for all treatment options. The apical third showed the highest area percentage of the remaining filling material followed by the middle then the coronal level.

Pairwise comparisons showed that the value found at the apical level to be significantly higher than that found at the coronal level for all treatment groups $(p<0.001)$, comparison between middle and apical levels showed no significant difference for ultrasonic and Endostar retreatment groups (Figures 2 and 3).

\section{Discussion}

Retreatment is considered a valid alternative for extraction in case of failure of primary endodontic treatment. The complete removal of root filling material is difficult, and it is one of the main goals of non-surgical endodontic retreatment procedure. Attaining this goal can be achieved by accessing the apical foramen as well as the action of endodontic instruments and irrigating solutions used during instrumentation. This procedure effectively eliminates the necrotic tissue and remaining microorganisms [3], [5], [8], [12], [13].

The literature shows that no instrument or technique can completely remove root canal filling materials from the root canal system during non-surgical root canal retreatment [1], [3], [13], [14], [15], [16], [17] which can ultimately result in treatment failures because of the inability to eliminate microorganism from the root canal system [4]. Therefore, new instruments and supplementary protocols for remaining filling material removal have been proposed [5], [18], [19], [20].

Mandibular first premolars were considered for this in vitro study as they are frequently extracted for orthodontic reasons and their canals are often straight and flattened mesiodistally. This study did not control apical size for retreatment, and protocol was followed according to the manufacturers' instructions.

To the best of our knowledge, there are no previous studies that compared gutta-percha removal of Rogin retreatment $\mathrm{Ni}-\mathrm{Ti}$ rotary instrumentation system and Endostar RE Re endo retreatment rotary $\mathrm{Ni}-\mathrm{Ti}$ instrumentation system, which are distinctly different in their design and number of files to be used. In this study, $2.6 \% \mathrm{NaOCl}$ was used as a routine irrigation during cleaning and shaping procedures because of its broad antibacterial effect and organic material dissolution ability. Unlike, the high concentration of $\mathrm{NaOCl}(5.25 \%)$ which is highly toxic and causes degradation of the dentin matrix components thereby affecting the mechanical properties of the teeth. Since

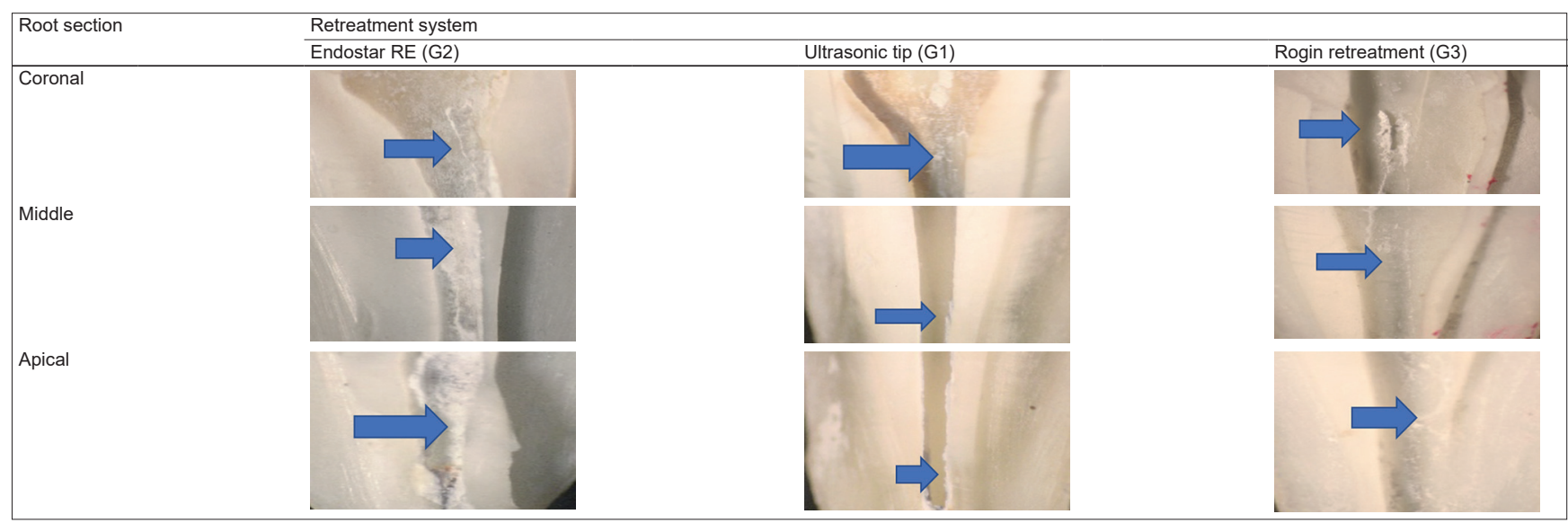

Figure 3: Stereomicroscopy of a specimen after retreatment for different systems and for coronal, middle, and apical thirds 
$\mathrm{NaOCl}$ lacks the ability to dissolve inorganic material, the smear layer was removed using $3 \mathrm{ml}$ of $17 \%$ EDTA, then $10 \mathrm{ml}$ distilled water was used immediately after EDTA to avoid the prolonged effect of the chelating agent on the root dentine microhardness [8], [9], [15].

The use of solvent as an aid in removing the filling mass is somewhat controversial. A solvent can facilitate penetration of the instrument into the filled canal, but its use may result in the formation thin and hard to remove layer of filling material adhered to the dentinal walls. During the removal of filling material, solvents were not used because the previous studies found that the use of solvents led to more remnants of gutta-percha and sealer on the root canal walls and inside the dentinal tubules [4], [5], [12].

Different practices have been employed toassess the amount of the residual obturation material after the retreatment procedures as clearing methods, radiography, cone-beam computed topography, scanning electron microscope, and stereomicroscope [2], [15], [17], [19]. Our specimens were longitudinally split and the percentage of the residual obturation material was determined from images captured under stereomicroscope. This method is considered more reliable than radiographic evaluation which only provides a two-dimensional view. Furthermore, this method can determine the amount of the remaining filling material and minimize the subjectivity associated with the scale-based scoring method. Recently, microcomputed tomography has shown efficacy in assessing the retreatment techniques in three dimensions without specimen destruction. However, there is a limited access to the device.

Temperature changes that occur in the oral cavity may produce different thermal expansion coefficients between tooth structure and filling material that may affect the bond strength and consequently the removal capacity during retreatment [21], [22]. The removal of filling materials during retreatment procedures enables instruments and irrigants to reach all areas of the root canal system, which results in more effective intracanal cleaning and disinfection. According to a review, no existing retreatment protocol can completely remove root filling materials. The mean percentage of residual material ranges from $45.4 \%$ to $0.02 \%$. Even in the present study, complete removal of sealer and gutta-percha using the different compared techniques was not achieved [3], [5], [8].

Numerous devices have been used to remove the filling material from the root canals such as stainless steel hand files, $\mathrm{Ni}-\mathrm{Ti}$ files, lasers, and ultrasonic files. The use of conventional files to remove a wellcondensed obturating material has relatively been a tiresome and laborious procedure for the operator and might also lead to endodontic accidents [10], [17], [20].

To increase safety during retreatment procedures and to produce more adequate shaping, retreatment files have been designed with non-cutting tips, radial lands, varying tapers and rake angles, and changing pitch lengths. In the present study, we found the ultrasonic retreatment tips (G1) to be significantly more efficient in removing the gutta-percha and sealers from the canal than other instrumentation methods. Similar results were obtained by RachedJúnior et al. [18] who found that the ultrasonic retreatment instrument removed more obturation material than other group. This could be explained on the basis that the ultrasonic vibrations emerging from the ultrasonic tip facilitate the dislodgement of filling material from the root canal walls enabling the removal of the sealer. The heat that gets generated by the ultrasonic instrument due to friction results in an additive effect on gutta-percha causing softening and dislocation of gutta-percha from the root canal. The increased amount of the debris in the apical third may be attributed to the increased diameter along the tip of ultrasonic tip which is more than that of the master apical file's diameter and so the tip may not completely reach the apical area.

These results may be associated with the tip vibration, which promotes acoustic transmission resulting in the breakage and displacement of the remaining filling material from the root canal walls [5], [8], [16], [19], [23]. It can also promote temperature increase [2], [15], [23] which may alter the filling material structure facilitating its removal through constant irrigation. In addition, the flat triangular design of the ultrasonic tip associated with pendulum movements allows a better adaptation to the root canal anatomy, touching on the polar and escape areas, facilitating the removal of the remaining filling material, and leaving its fragments distributed along the root canal.

Ultrasonic waves allow the tip to freely move inside the canal which is essential for easy irrigant penetration and provides a strong cleaning effect. The energy is conveyed through ultrasonic waves from the file to the irrigant produce two physical phenomena: Acoustic stream and irrigant cavitation. The acoustic stream is the rapid fluid movement in circular or vortex cavitation is the distortion of shape around the file, while the existing bubbles in the irrigant. In addition, ultrasonic retreatment tip removes sealer and gutta-percha debris from areas that are inaccessible to conventional retreatment files. This could be attributed to gutta-percha plasticization caused by tip. The combined actions of ultrasonic vibration and frictional heat enabled the displacement of the filling material and gutta-percha from the walls of the root canal [7], [8], [12].

The use of crown-down technique in the Rogin retreatment $\mathrm{Ni}-\mathrm{Ti}$ rotary instrumentation system with early flaring of the coronal part of the preparation improves instrument control during the preparation of apical one-third of the canal. It was observed that rotary instrumentation for gutta-percha removal tends to pull 
the dentinal debris into the file flutes and direct it toward the coronal aspect of the canal [10], [13].

Rogin retreatment $\mathrm{Ni}-\mathrm{Ti}$ rotary instrumentation system has a convex triangular cross-section with three machined cutting edges which results in decreased cutting efficiency and smaller dentin chip space. The apical D3 file with a larger taper of $7 \%$ and tip diameter $0.20 \mathrm{~mm}$ may attribute to more apical remaining gutta-percha. In Endostar RE retreatment rotary $\mathrm{Ni}-\mathrm{Ti}$ instrumentation system, file nos. 1 and 2 have square cross-section similar to K-files with four cutting edges and good elasticity while No. 3 and No. 4 have S-crosssection with cutting taper/tip diameter of $0.06 / 30$ and 0.04/30, respectively. Residual gutta-percha percentage may be attributed to S-cross-section design of No. 3 and No. 4 files which provides positive rake angle with two cutting edges distributed symmetrically, increased pitch length, and more cross-sectional space for enhanced cutting and allowing the debris to move coronally.

Rogin retreatment $\mathrm{Ni}-\mathrm{Ti}$ rotary instrumentation system good performance may be attributed to their design features. The system comprises three instruments: D1, D2, and D3 which show progressive lengths and tapers, enabling them to cut the gutta-percha and the superficial dentine layer during the removal of obturation materials. Furthermore, the flute design as well as the rotary motion tend to pull the gutta-percha toward the file flutes and guide it toward the orifice of the canal. Moreover, the rotary motion produces frictional heat which plasticizes the gutta-percha, rendering it less resistant and easier to remove [15].

Given the results of the present study, the complete removal of filling material during nonsurgical root canal retreatment remains a challenge in endodontics. Thus, the development of new techniques, instruments, or solutions aiming to promote the complete removal of the filling materials from the root canal system presents clinical significance. The results obtained here suggest that supplementary techniques are able to reduce the volume of remaining filling materials. Ultrasonic tips may be considered a good option. Moreover, the evaluated techniques were not able to promote complete root canal filling material removal from the root canal system.

\section{Limitations}

The limitations of the present study were having a relative small sample size. Moreover, the findings cannot be explorated to all types of teeth as the samples used in this study relatively have straight roots. The results of this study cannot be generalized to multiple rooted teeth, curved canals, open apices, and incomplete root development cases. In addition, the use of a non-destructive method such as microcomputed tomography, in evaluation of the residual root filling materials, is recommended.

\section{Conclusions}

Within the parameters of this study, ultrasonic retreatment tip file was found to be effective in the removal of root canal filling material followed by Rogin retreatment $\mathrm{Ni}-\mathrm{Ti}$ rotary instrumentation system and Endostar $\mathrm{RE}$ retreatment rotary $\mathrm{Ni}-\mathrm{Ti}$ instrumentation system. Nevertheless, we observed incomplete removal of gutta-percha and sealers from root canals in all experimental groups. Under the limitations of this in vitro study, it can be concluded that the retreatment techniques used were incapable of complete removal of the filling materials from the root canal walls.

\section{Clinical Relevance}

Clinicians should be aware of the new endodontic systems introduced in the dental field, their properties, application, and their retreatment efficacy to be able to have a proper management achieving favorable retreatment outcomes.

\section{Ethical Approval}

The protocol was approved by the Committee of Research Ethics, Faculty of Dentistry, October 6 University, with approval number RECO6U/7-2021 and approval date June 3, 2021.

\section{References}

1. Pawar AM, Pawar SM, Pawar MG, Kokate SR. Retreatment of endodontically failed tooth with wide-open apex using platelet rich fibrin membrane as matrix and an apical plug of Biodentine ${ }^{\mathrm{TM}}$. Eur J Gen Dent. 2015;4(3):150-4. https://doi.org/10.4103/2278-9626.163341

2. Duncan HF, Chong BS. Removal of root filling materials. Endod Top. 2011;19:33-57.

3. Hammad M, Qualtrough A, Silikas N. Three-dimensional evaluation of effectiveness of hand and rotary instrumentation for retreatment of canals filled with different materials. J Endod. 2008;34(11):1370-3. https://doi.org/10.1016/j.joen.2008.07.024 PMid:18928849 
4. Imura N, Zuolo ML, Ferreira MO, Novo NF. Effectiveness of the Canal Finder and hand instrumentation in removal of gutta percha root fillings during root canal retreatment. Int Endod J. 1996;29(6):382-6. https://doi.org/10.1111/j.1365-2591.1996. tb01402.x

PMid:10332238

5. Keles A, Koseoglu M. Dissolution of root canal sealers in EDTA and $\mathrm{NaOCl}$ solutions. J Am Dent Assoc. 2009;140(1):74-9. https://doi.org/10.14219/jada.archive.2009.0021

PMid:19119170

6. de Oliveira DP, Barbizam JV, Trope M, Teixeira FB. Comparison between gutta-percha and Resilon removal using two different techniques in endodontic retreatment. J Endod. 2006;32(4):362-4. https://doi.org/10.1016/j.joen.2005.12.006 PMid: 16554213

7. Ring J, Murray PE, Namerow KN, Moldauer BI, Garcia-Godoy F. Removing root canal obturation materials: A comparison of rotary file systems and re-treatment agents. J Am Dent Assoc. 2009;140(6):680-8. https://doi.org/10.14219/jada. archive.2009.0254

\section{PMid:19491164}

8. Schirrmeister JF, Wrbas KT, Schneider FH, Altenburger MJ Hellwig E. Effectiveness of a hand file and three nickel titanium rotary instruments for removing gutta-percha in curved root canals during retreatment. Oral Surg Oral Med Oral Pathol Oral Radiol Endod. 2006;101(4):542-7. https://doi.org/10.1016/j. tripleo.2005.03.003

PMid: 16545721

9. Bernardes RA, Duarte MA, Vivan RR, Alcalde MP Vasconcelos BC, Bramante CM. Comparison of three retreatment techniques with ultrasonic activation in flattened canals using micro-computed tomography and scanning electron microscopy. Int Endod J. 2016;49(9):890-7. https://doi. org/10.1111/iej.12522

PMid:26280904

10. Pawar AM, Thakur B, Metzger Z, Kfir A, Pawar M. The efficacy of the self-adjusting file versus WaveOne in removal of root filling residue that remains in oval canals after the use of ProTaper retreatment files: A cone-beam computed tomography study. J Conserv Dent. 2016;19(1):72-6. https://doi. org/10.4103/0972-0707.173204

PMid:26957798

11. De-Deus G, Belladonna FG, Zuolo AS, Cavalcante DM, Carvalho MS, Marinho A, et al. 3-dimensional ability assessment in removing root filling material from pair-matched ovalshaped canals using thermal-treated instruments. J Endod. 2019;45(9):1135-41. https://doi.org/10.1016/j.joen.2019.06.003 PMid:31350048

12. Koçak MM, Koçak M, Türker S, Sağlam BC. Cleaning efficacy of reciprocal and rotary systems.in the removal of root canal filling material. J Cons Dent. 2016;19(2):184.

13. Bago I, Suk M, Katić M, Gabrić D, Anić I. Comparison of the effectiveness of various rotary and reciprocating systems with different surface treatments to remove gutta-percha and an epoxy resin-based sealer from straight root canals. Int Endod J. 2019;52(1):105-13. https://doi.org/10.1111/iej.12985 PMid:29985524

14. Tambe VH, Nagmode PS, Vishwas JR, Saujanya KP, Angadi $P$, Ali FM. Evaluation of the amount of debris extruded apically by using conventional syringe, endovac and ultrasonic irrigation technique: An in vitro study. J Int Oral Health. 2013;5(3):63-6. PMid:24155604

15. Virdee SS, Thomas MB. A practitioner's guide to guttapercha removal during endodontic retreatment. $\mathrm{Br}$ Dent $\mathrm{J}$. 2017;222(4):251-7. https://doi.org/10.1038/sj.bdj.2017.166 PMid:28232689

16. Zuolo AS, Mello JE Jr., Cunha RS, Zuolo ML, Bueno CE. Efficacy of reciprocating and rotary techniques for removing filling material during root canal retreatment. Int Endod $\mathrm{J}$. 2013;46(10):947-53. https://doi.org/10.1111/iej.12085 PMid:23506150

17. Alves FR, Marceliano-Alves MF, Sousa JC, Silveira SB, Provenzano JC. Removal of rootcanal fillings in curved canals using either reciprocating single-or rotary multiinstrument systems and a supplementary step with the XP-endo Finisher. $\mathrm{J}$ Endod. 2016;42(7):1114-9. https://doi.org/10.1016/j. joen.2016.04.007

PMid:27215810

18. Rached-Junior FA, Sousa-Neto MD, Bruniera JF, Duarte MA Silva-Sousa YT. Confocal microscopy assessment of filling material remaining on root canal walls after retreatment. Int Endod J. 2014;47(3):264-70. https://doi.org/10.1111/iej.12142 PMid:23895052

19. Bodrumlu E, Uzun Ö, Topuz Ö, Semiz M. Efficacy of 3 techniques in removing root canal filling material. J Can Dent Assoc. 2008;74(8):721.

PMid:18845062

20. Saad AY, Al-Hadlaq SM, Al-Katheeri NH. Efficacy of two rotary $\mathrm{NiTi}$ instruments in the removal of gutta-percha during root canal retreatment. J Endod. 2007;33(1):38-41.

PMid: 17185127

21. Tanomaru-Filho M, Tanomaru JM, Leonardo MR, da Silva LA Periapical repair after root canal filling with different root canal sealers. Braz Dent J. 2009;20(5):389-95. https://doi. org/10.1590/s0103-64402009000500006 PMid:20126907

22. Saghiri MA, Asatourian A, Garcia-Godoy F, Gutmann JL, Sheibani N. The impact of thermocycling process on the dislodgement force of different endodontic cements. Biomed Res Int. 2013;2013:317185.

23. Rossi-Fedele G, Ahmed HM. Assessment of root canal filling removal effectiveness using micro-computed tomography: A systematic review. J Endod. 2017;43(4):520-6. https://doi. org/10.1016/j.joen.2016.12.008

PMid:28214018 